the cases the cataract in the eye, which had become cataractous in the second place only, was still immature at the time of operation.

\section{CASES OF DUODENAT PERFORATION.}

BY ANDREW CLARK, M.D., F.R.C.P., Physician to and Lecturer on Medicine at the London Hospital.

As I was passing through the hospital on June 10th, a man was brought into Harrison Ward, complaining of severe pain in the right side of the belly; and I was requested to examine and prescribe for him.

In answer to my questions, he said that he had breakfasted as usual about eight o'clock; that between nine and ten, he had taken some of a mixture which his doctor had sent him for a slight indigestion, that immediately afterwards he was seized with pain which grew in severity up to the time of admission into the hospital, and that he was in his own opinion suffering from the effects of some mistake in the preparation of his physic.

The patient, 35 years of age, was a moderately well nourished, fresh coloured, and altogether healthy looking man. Reclining upon the bed, he uttered frequent groans, and turned restlessly from side to side. The legs were sometimes straightened, and sometimes bent, as it were, indifferently. The belly was flat, and its walls were rigid. His constant and sole complaint was pain, and its chief seat was in the right side between the situation of the free margin of the liver and the groin. Shortly afterwards the pain extended upwards into the right shoulder and downwards into the right testicle which was not, however, retracted. The pain was not increased either by pressure or by change of position, and the patient bore free examination of all parts of the belly without apparent increase of suffering. The tongue was clean and moist. There was neither nausea nor vomiting; the bowels had been moved naturally two days before admission; urine passed a little before my examination was quite healthy; the pulse was about 76, of natural fulness and strength; the extremities were warm.

Of the man's condition before the attack, all that could be made out was that he had occasionally suffered from slight indigestion; that he was so suffering in a small degree when he became ill; and that once at least he had been jaundiced; he had never, however, had pain after food or vomiting.

Such were the chief facts of the case. What was their interpretation? Obviously enough the patient was not suffering from the effects of any irritant poison. Was it gastric or intestinal perforation? There was certainly a history of slight indigestion, and the pain was excruciating; but eight hours had elapsed since its commencement, and still there was neither collapse nor evidence of peritoneal inflammation, and the ingestion of fluid was followed by no increase of suffering. Was it a renal calculus? There was pain in the region of the kidney passing downwards and forwards into the groin and testicle; but then the urine was healthy; there was no history of any kind of gravel; the testicle was not retracted; and the pain was more severe even than that which commonly attends the passage of a concretion from the kidney into the bladder. Could it be a gallstone? 'True, there had been indigestion, and once at least a little jaundice. True also, there were now pain in the right side of the belly, not increased by pressure; pain in the right shoulder and arm, and a quiet pulse; but, on the other hand, there was neither nausea, nor vomiting, nor flatulence; and there was no sense of constriction about the epigastrium. The pain suffered by the patient was burning instead of boring; continuous; less in the region of the liver than lower down; and ranged over a wider space than I had ever known the pain of a biliary calculus to range. The notions of colic, strangulation, typhlitis, and the like, were dismissed from the mind almost as soon as they arose. The case was somewhat obscure: I feared perforation, but chose to suspend my judgment till the next visit, which $I$ proposed to maks a few hours afterwards. Meanwhile the patient was restricted from food; a full dose of opium was prescribed, and ordered to be repeated in half doses at short intervals; hot flannels sprinkled with turpentine were applied to the belly.

An hour after leaving the patient, I had an urgent summons to Leytonstone, and was unable to see him again alive. I am, therefore, indebted to Dr. James Jackson for the subsequent history of the case.

The patient was relieved by the opium, and remained during the afterncon and evoning in tolerable comfort; but in the middle of the night, Dr. Jackson was summoned in great haste on account of a sudden return of the pain, and its rapid diffusion throughout the whole abdomen. On Dr. Jackson's arrival he found the man lying on his back with his knees drawn up; the belly was much swollen and exquisitely tender; the features were contracted and anxious; the pulse was quick, small, feeble, and irregular; and the skin cold, dark, and covered with a clammy sweat. General peritonitis had set in. There was no longer any doubt as to the nature of the case; it was one of perforation. After six hours of extreme suffering, the patient died.

On examining the body after death, the peritoneal cavity was found to contain much flaky serum; the coils of intestine were lightly glued together by recently effused lymph spotted with blood, and just below the middle of the liver the pancreas and first part of the duodenum were bound together by a mass of partly old and partly recent lymph. At one side of this mass was discovered a rugged opening, about half an inch in its greatest diameter, which communicated with the cavity of the bowel. When the duodenum was laid open, the perforation was seen to have occurred at one side of the base of an ulcer situated about half an inch from the pyloric orifice of the stomach. The ulcer measured $\frac{5}{8}$ by $\frac{7}{8}$ of an inch in diameter, and had sharp shelving margins getting narrower towards the base, which was formed by peritoneum thickened outside by layers of tolerably firm lymph. One could see clearly that they had been formed at different times. On the opposite side of the bowel, but a little further down, there was noticed a shallow circular depression about a quarter of an inch in diameter, with rounded margins and a smooth whitish base, composed of fibroid tissue, clothed with a single layer of flattened cells. It resembled, and probably was, the cicatrix of an ulcer.

There were several minute erosions in the pyloric half of the mucous membrane of the stomach.

No disease was discovered elsewhere.

There are two or three points in this case worthy of passing notice. In the first place it is plain that ulcers must have formed and healed, or remained open, without causing other than trifling disturbances of digestion. The most careful inquiry elicited nothing more than that the patient was occasionally out of sorts, and had just before death been under treatment for some slight indigestion called " biliousness." But there was no history of pain after food or of vomiting.

$A$ second point of interest in this case was the long continuance of pain, due to leakage into the 
peritoneal cavity, unaccompanfed by other local or any constitutional disturfance. "For over sixteen hours the man suffered from pain, varying it is true in intensity, bat throuthout serere, and yet the tongue remained clean; there wats no rothiting ; the belly could be pressed withut inbticeable increase of suffering; the palse never rose above 80, and the skin remained warm and moist until the setting in of general peritonitis:

Lastly, for those sixteen hours the pain was confined to one side; it is probable, therefore, that the hearty breakfast caused; 'by distension, ' $a$ ' slight leakage from the ulcer, great enough to produce agonising pain, but too sman to induce general inflammation; and in this condition one can easily understand how, with due etre and rigid abstinence from food and drink, nature might have securely stopped the leak with lymph; but in the present case, either from too light a warning on my pant, or too weak a resolution on the part of the patient, this abstinence was not praotised. Late in the evening, urged by a thirst which the patient could or would not resist, he drank freely of fluid, which, thaking the little leak a rent, escaped into the cavity of the peritoneum, and lit up the inflammation which put an end to his life.

On reviewing my experience of cases like the one I have related, I camnot doubt that occhsionally small perforations ocearring in both gastric and intestinal ulcers are stopped by lymph before fatal injury is done to the patient in oonsequence of the escape of fluid into the peritoneal sac, and I shall further on relate a case which appears to support this view; but to secure so liappy an issure for so perilous an accident it seems esseritibl that the patient should be kept in a state of absolute repose; that he should take by the stomach neither solid nor liquid food for four and twenty hours at least, ind that he should have full, and sometimes, if there be much restlessness, frequent doses of opium.

[To be continued.]

\section{CASE OF POST-PARTUM HAMORRHAGE, IN WHICH THE ETHER-SPRAY WAS SUCCESSFULLY USED.}

By John Broadbent, M.R.C.S., etc., Manchester.

AT $10 \frac{1}{2}$ P.M. on April 3rd, 1867, I was called to see Mrs. T., in labour of her twelfth child. I found the os uteri only slightly dilated, and the pains weak. The breech presented, and the child was born the following morning, without anything unusaal occurring. The placenta was adherent, and required the introduction of the hand for its removal. Profuse hæmorrhage followed; and though the usual remedies, including ergot, cold napkins to the vulva, etc., and introduction of the hand into the uterus, were employed, the bleeding continued, and the woman became almost pulseless, and was evidently sinking fast. The hand in the uterus moved about as if in a wet bladder, little or no contraction being excited by it. My friend Mr. Harrison saw the case with me, and I proposed to him to apply the etherspray to the hypogastric region. This I did, using the double jet; and very soon the uterus began to contract, and the hæmorrhage ceased. There was no relaxation of the uterus after; and the woman ultimately made a good recovery, though very anmmic for some time after. The hæmarrhage was evidently due to uterine inertia; and the effect of the etherspray in producing contraction of the organ was very marked after the failure of the remedies used before it.
A CASE OF INDUCTION OF LAABOUR A SECOND TIME IN A WOMAN WITH

\section{A DEFORMED SPINE AND PELVIS.*}

Bx John Arastrong, M.D., Gravesend.

WhEN we had the pleasure of your presence here twelve months since, $I$ read a paper on the induction of premature labour, and narrated a case in which I had induced labour, with the results. I attempted to give a brief outline of the introduction of that operation into the profession, and the varions modes of effecting it up to the present time. As the same patient became pregnant again, and I had to resort to this remedy, and as there are some circumstances of interest peculiar to this last delivery, I thought I should not be occupying the time of the meeting unprofitably to narrate them. The records of my notebook I transcribe.

September 1866. Mrs. S. was again pregnant. She had seen Dr. Hicks several times; and I tried to get hen to go up to Guy's to be delivered by Dr. Hicks, but could not succeed.

Oct. 19th. She said she was last unwell on the 18th of February. Her husband was at home about a week afterwards. The calculation was, that she was nearly eight months gone. On examining her, with great difficulty I reached the os; but I could not make out any part of the foetus. The os seemed, as on former occasions, not directed down in the axis of the pelvis, but as if the uterus lay straight down in the abdomen, with the os directed towards the anterior wall. I prescribed for her ten grains of powdered ergot every four hours, with the hope that some uterine action would cause the os to be directed more towards the pelvis.

Oct. 20th. The os lay in the same position. It was useless to attempt to introduce Dr. Barnes's dilators, unless the hand were introduced into the pelvis to apply the dilators. I therefore resorted to the gum-elastic catheter, which I introduced with some difficulty. After I had passed it up four or five inches, I withdrew the stilette, and passed it up quite eight inches.

Oct. 21st. Twenty-four hours had elapsed with scarcely any sense of pain. I withdrew the catheter; and, when about four inches were in the uterus, $I$ passed it with my finger round the cervix, so as completely to detach the membranes at that part. In the evening, word was sent me that the waters had broken. I found the os still up, anteverted, and a little open. She was straining violently; pulse weak and quick. She complained of faintness. I required her not to strain at present; and, as she had had no sleep for forty-eight hours, I gave her forty minims of laudanum.

Oct. 22nd. She had had several hours' sleep. At 6 A.M., pains returned, having a more regular character; and, about 7.30, a small female infant was expelled. I removed the placenta. There was no hæmorrhage. The child was living; it was small, and had a small compact head, and was likely to live. Her recovery was excellent.

March 18th, 1867. I saw the mother and child today. The child is really a fine, well-grown, and wellnourished child, and would bear comparison with children of the same age:

$I$ would remark, in conclusion, that this is a very

* Read at the Distriot meeting held at Gravesend March 29, 1867. 